\title{
As múltiplas territorialidades das lanchas de passageiros no rio solimões
}

\section{The multiple territorialities of the passenger speedboats on the river solimões}

DOI: $10.54018 /$ sssrv3n1-002

Recebimento dos originais: $30 / 11 / 2021$

Aceitação para publicação: 23/12/2021

\section{Kristian Queiroz}

E-mail:kssqueiroz@gmail.com

\section{RESUMO}

Este artigo propõe uma leitura das múltiplas territorialidades efetuadas pelas lanchas de transporte de passageiros no rio Solimões no Amazonas. O trabalho de campo e o levantamento bibliográfico subsidiaram a proposta de classificação destas lanchas a partir da origem dos seus fluxos. Isto permitiu compreender que as formas destas embarcações e a territorialidade empreendida modificam-se na medida em que se afastam de centros urbanos onde a densidade técnica e normativa do território são maiores.

Palavras-chave: Territorialidades. Lanchas de passageiros. Rio Solimões.

\section{ABSTRACT}

This article proposes a reading of the multiple territorialities carried out by the passenger speedboats on the Solimões River in the Amazon. The field work and the bibliographic survey subsidized the proposed classification of these fast boats from the origin of their flows. This made it possible to understand that the forms of these boats and the territoriality undertaken change as they move away from urban centers where the technical and normative density of the territory is greater.

Keywords: Territorialities. Passenger Speedboats. Solimões River.

\section{RESUMEN}

Este artículo propone una lectura de las múltiples territorialidades efectuadas por las lanchas de transporte de pasajeros en el río Solimões en el Amazonas. El trabajo de campo y el levantamiento bibliográfico subsidiaron la propuesta de clasificación de estas lanchas a partir del origen de sus flujos. Esto permitió comprender que las formas de estas embarcaciones y la territorialidad emprendida se modifican en la medida en que se alejan de centros urbanos donde la densidad técnica y normativa del territorio son mayores.

Palabras clave: Territorialidades. Lanchas de pasajeros. Río Solimões. 


\section{INTRODUÇÃO}

A busca pela intensificação dos fluxos no transporte fluvial do rio Solimões no estado do Amazonas promoveu o desenvolvimento do segmento da circulação fluvial que oferece a aceleração e a velocidade como vantagens frente ao desempenho que os tradicionais barcos dessa região não proporcionam, permitindo a diminuição na duração das viagens intermunicipais na região.

Estas embarcações da navegação regional de passageiros conhecidas como lanchas "Ajato" ou "expressos", se configuram como o produto de uma modernização aquaviária vinculada à especialização do lugar (QUEIROZ, 2017a), representando objetos geográficos que realizam o que Harvey (2005, p.47) chama de "anulação do espaço pelo tempo" (Figura 1).

Figura 1 - As lanchas do transporte fluvial no rio Solimões.

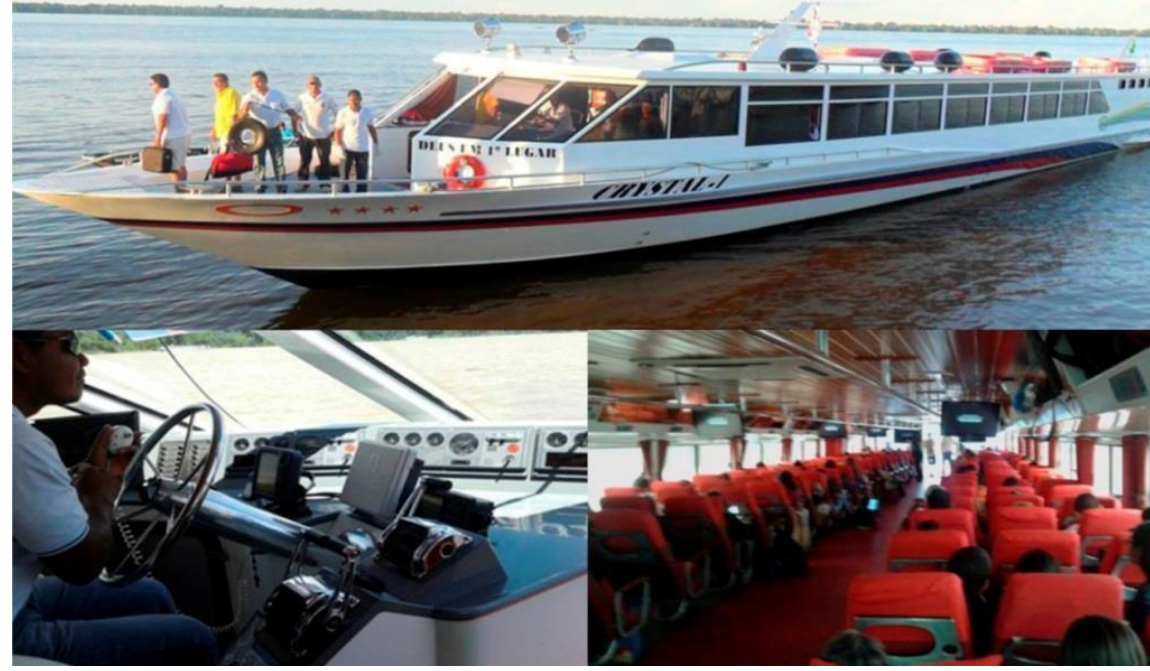

Fonte: Acervo do autor, 2016.

O segmento Lancha-Motor $(\mathrm{L} / \mathrm{M})$ da circulação de passageiros no rio Solimões, acaba por contemplar a combinação das necessidades do cotidiano regional e a expansão de novas técnicas advindas de uma divisão territorial do trabalho proveniente de espaços luminosos. Isto provoca uma dialética do território, o confronto dialogado entre o velho e novo, o local e o global, entre as verticalidades e as horizontalidades (SILVEIRA, 1999a, p.400).

Neste sentido, o objetivo deste artigo é analisar as múltiplas territorialidades realizadas pelas lanchas do transporte fluvial de passageiros no rio Solimões no estado do Amazonas.

Evidencia-se que rotas distintas e diferentes tipos de lanchas estabelecem uma rede ligando a determinados nodais de embarque e desembarque de passageiros. Esta pesquisa parte da hipótese de que estas lanchas têm suas formas modificadas na medida em que suas funções se adaptam à estrutura 
técnica e normativa do território; o que ocorre em espaços distantes dos centros urbanos onde a assistência técnica disponível é menor. Assim, a configuração territorial provoca a adequação e desenvolvimento de novas formas de territorialidades e controle dos fluxos que interagem com as exigências do cotidiano dos diversos tipos de passageiros do Solimões.

O trabalho de campo realizado nos $1.620 \mathrm{~km}$ do Solimões e as entrevistas com passageiros, armadores ${ }^{i}$ e empresários principalmente nas cidades de Tefé, Coari, Tabatinga, Santo Antônio do Iça e Manaus, subsidiaram a aquisição de dados primários. Este respectivo percurso que compreende a capital Manaus e a cidade de Tabatinga na tríplice fronteira do Brasil com o Peru e Colômbia possibilitou a observação dos fixos especializados na navegação regional no estado assim como o reconhecimento dos agentes e embarcações que permitem os fluxos neste subespaço fluvial. O levantamento bibliográfico assim como as visitas institucionais na Agência Nacional de Transportes Aquaviários (ANTAQ) em Manaus e nos Terminais Hidroviários dos municípios de Tabatinga, Tefé, Tonantins, Codajás, Coari e Fonte Boa geridos pela Administração Hidroviária da Amazônia Ocidental (AHIMOC) e o Departamento Nacional de Infraestruturas de Transportes (DNIT) subsidiaram o levantamento de dados secundários.

Tornou-se fundamental à pesquisa conhecer a origem dos fluxos para delimitar categorias de análise em função das sedes ou cidades onde estão localizados portos, entrepostos fluviais e terminais hidroviários na extensão do rio Solimões. A partir desta categorização a hipótese da ocorrência de múltiplas territorialidades pode ser lida na medida em que as técnicas e infraestruturas das lanchas são modificadas quanto mais se afastam do ponto primordial de irradiação dos fluxos. Desta maneira, classifica-se as lanchas a partir dos fluxos primários, secundários e terciários efetuados por estas embarcações (Figura 2). 
Figura 2 - Proposta de classificação de acordo com a origem dos fluxos das lanchas no Solimões

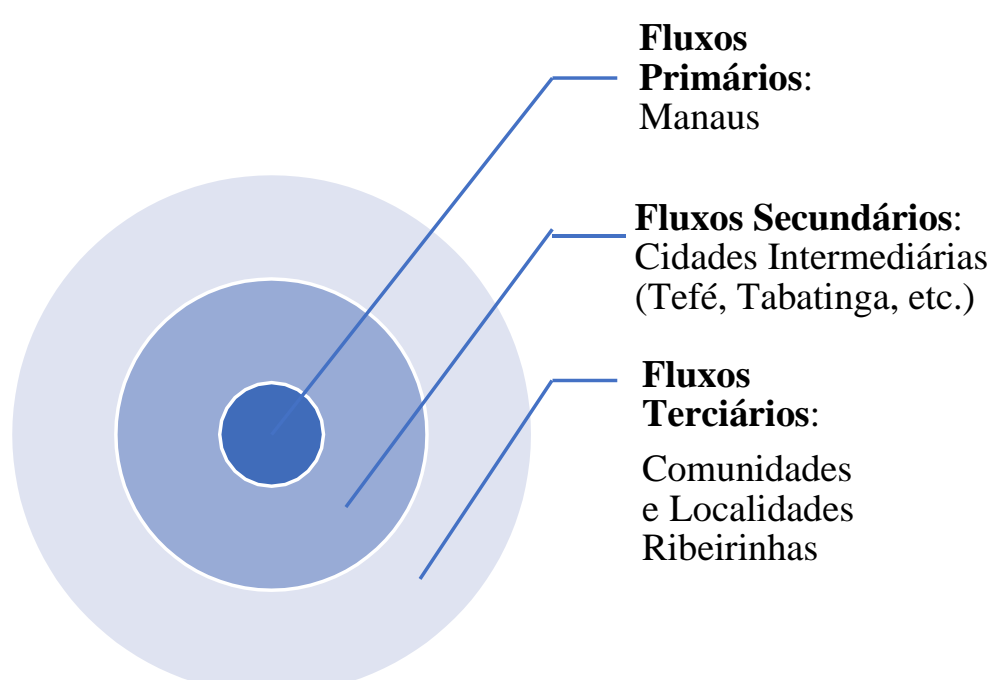

Fonte: Confecção própria, 2018.

Por conseguinte, define-se as lanchas dos fluxos primários como as advindas da capital Manaus, do porto conhecido como "Manaus Moderna" no rio Negro de onde zarpam as lanchas Ajato para o rio Solimões, área de estudo desta pesquisa. Estas lanchas são as mais modernas e atendem a todas as cidades do rio Solimões, cidades que os outros segmentos da navegação regional não atendem. Contam com o suporte de terminais da empresa Ajato em Manaus e Tefé assim como dos postos de combustíveis flutuantes do Solimões, os "Pontões". Estas lanchas operacionalizam de assistência técnica e profissional presentes na metrópole Manaus de onde se originam seus fluxos e a densidade técnica e informacional são pertinentes ao meio geográfico contemporâneo.

As lanchas dos fluxos secundários realizam fluxos provenientes das cidades intermediárias do rio Solimões, tais como: Tefé, Coari, Fonte Boa, Jutaí e Tabatinga, e de seus afluentes como da cidade de Juruá no rio Juruá. A hinterlândia das cidades de Tefé e Tabatinga corrobora para fluxos significativos das lanchas desta categoria secundária. Isso ocorre em função de Tefé se configurar como o maior centro urbano e possuir a maior região de influência no estado depois da capital Manaus e Tabatinga por contar com alta frequência de 
fluxos ao seu entorno, pertinente à tríplice fronteira entre o Brasil, a Colômbia e o Peru. São lanchas menores e com menos equipamentos modernos em relação as embarcações dos fluxos primários.

Classifica-se as lanchas dos fluxos terciários como as que conectam as centenas de comunidades ribeirinhas localizadas nos rios, furos, paranás e igarapés da bacia do Solimões entre seus afluentes. São ainda menores que as secundárias e atendem às exigências da configuração territorial existente o que Queiroz (2017a) chama de uma "modernização pretérita". Esta categoria efetua fretamentos para firmas, instituições e indivíduos. Não contam com nenhum tipo de equipamentos e instrumentos, porém utilizam um potente motor para acelerar e reproduzem o designer estilo "manaura" das lanchas maiores, um símbolo que identifica estas embarcações do transporte fluvial de passageiros no rio Solimões.

\section{AS LANCHAS DE PASSAGEIROS DO SOLIMÕES}

Para uma melhor reflexão sobre as múltiplas territorialidades efetuadas pelas lanchas do transporte fluvial no Solimões referencia-se Silveira (1999a, p.416) quando discute que:

Reconheceríamos dois subtipos de geografia luminosa. De um lado, a luminosidade primária, na qual, embora as configurações territoriais apareçam como empecilhos à nova modernidade, são acolhidas as instâncias de controle no comando do território (...). E, de outro lado, mencionamos a luminosidade secundária, de segundo grau, dependente. É o exemplo dos pontos da verticalidade que encarnam uma luminosidade submetida a difração. Dadas as possibilidades técnicas e organizacionais do período, as regiões tornam-se teleorganizadas, comandadas desde pontos longínquos. Redes hegemônicas e domésticas, por vezes convergentes, por vezes opostas, produzem uma nova territorialidade. Uma circulação veloz e um controle remoto são, talvez, as características fundamentais de um espaço movediço e inconstante da ordem global. (SILVEIRA, 1999a, p.416/417).

Desta forma, inspirado na reflexão da geografia luminosa de Silveira (1999a), este estudo classifica os fluxos das lanchas Ajato para discutir das territorialidades efetuadas de diferentes formas no território e que pode ser lida na medida em que as técnicas e infraestruturas são modificadas quanto mais se afastam do ponto primordial de irradiação dos fluxos.

De acordo com a origem dos fluxos classifica-se como Lanchas dos fluxos primários aquelas que partem de Manaus, capital do Amazonas, onde os 
elementos do meio técnico-científico-informacional são mais densos e atuantes na dinâmica do espaço. As lanchas dos fluxos secundários partem das cidades intermediárias do rio Solimões como Tefé e Tabatinga. E as lanchas dos fluxos terciários são provenientes das centenas de comunidades ribeirinhas localizadas nos rios, furos, paranás e igarapés da bacia do Solimões e seus afluentes. (Figura $3)$.

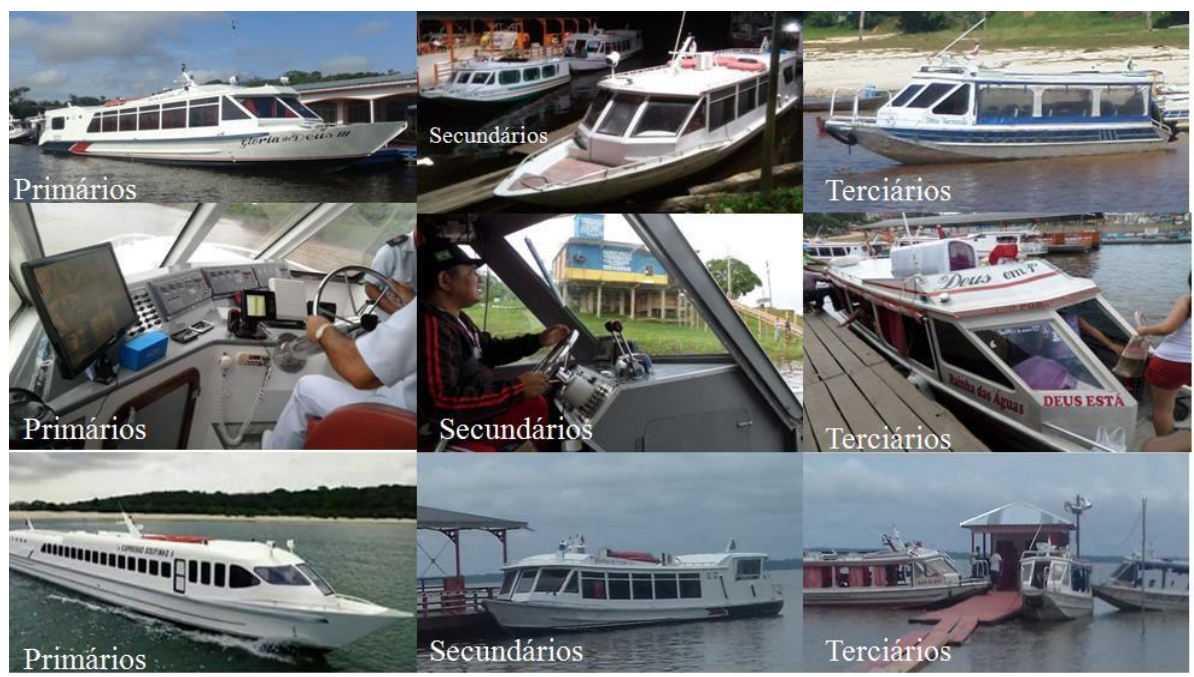

Figura 3 - As lanchas dos Fluxos Primários à esquerda; dos Fluxos Secundários no meio; e dos Fluxos Terciários à direita

Fonte: Acervo do autor, 2017.

As diferenças entre as lanchas atuantes em cada fluxo são relevantes, oferecendo técnicas e equipamentos modernos diferenciados durante o afastar de centros luminosos em função da acessibilidade disponibilidades destes no território (Quadro 1).

Quadro 1 - Os equipamentos das lanchas de acordo com o tipo de fluxos

\begin{tabular}{|c|c|c|c|c|c|c|}
\hline \multirow{2}{*}{$\begin{array}{c}\text { LANCHA } \\
\text { S }\end{array}$} & $\begin{array}{c}\text { GP } \\
\text { S }\end{array}$ & $\begin{array}{c}\text { Ecobatíme } \\
\text { tro }\end{array}$ & $\begin{array}{c}\text { Ar } \\
\text { Condicion } \\
\text { ado }\end{array}$ & $\begin{array}{c}\text { Rádio } \\
\text { (comunicaç } \\
\text { ões) }\end{array}$ & $\begin{array}{c}\text { TV } \\
\text { (Filme } \\
\text { s) }\end{array}$ & $\begin{array}{c}\text { Motore } \\
\text { s }\end{array}$ \\
\hline $\begin{array}{c}\text { Fluxos } \\
\text { Primários }\end{array}$ & $\begin{array}{c}\mathrm{Si} \\
\mathrm{m}\end{array}$ & $\mathrm{Sim}$ & $\mathrm{Sim}$ & Sim & Sim & $\begin{array}{c}\text { Alta } \\
\text { Potênci } \\
\text { a }\end{array}$ \\
\hline
\end{tabular}




\begin{tabular}{|c|c|c|c|c|c|c|}
\hline & & & & & & $\begin{array}{c}\text { (Acima } \\
\text { de } \\
500 \mathrm{HP} ; \\
\text { possue } \\
\text { m de } 1 \\
\text { a } 3 \\
\text { motores } \\
\text { ) }\end{array}$ \\
\hline $\begin{array}{l}\text { Fluxos } \\
\text { Secundár } \\
\text { ios }\end{array}$ & $\begin{array}{c}\text { Nã } \\
\text { o }\end{array}$ & Sim & Sim & Não & Não & $\begin{array}{c}\text { Alta/Mé } \\
\text { dia } \\
\text { Potênci } \\
\text { a } \\
\text { (possue } \\
\text { m } 1 \\
\text { motor } \\
\text { com até } \\
400 \text { HP) }\end{array}$ \\
\hline $\begin{array}{c}\text { Fluxos } \\
\text { Terciário } \\
\mathbf{s}\end{array}$ & $\begin{array}{c}\text { Nã } \\
\text { o }\end{array}$ & Não & Não & Não & Não & $\begin{array}{c}\text { Baixa } \\
\text { /Média } \\
\text { Potênci } \\
\text { a } \\
\text { (possue } \\
\text { m } 1 \\
\text { motor } \\
\text { com até } \\
225 \text { HP) }\end{array}$ \\
\hline
\end{tabular}

Fonte: Confecção própria, 2017.

Portanto, quanto mais distantes dos fluxos primários, ou seja, da rota principal no Solimões entre Manaus-Tabatinga, as funcionalidades dos fluxos secundários e terciários se apresentam maiores. As lanchas Ajato tornam-se objetos geográficos representantes da rapidez e da aceleração com a diminuição do espaço em função da aceleração do tempo.

\subsection{As lanchas dos fluxos primários do rio Solimões}

As lanchas pertinentes aos fluxos primários são as maiores e mais bem equipadas; representam a modernidade que possui as técnicas e estruturas contemporâneas como aliadas para vencer as grandes distâncias do Solimões.

A partir da metrópole Manaus, estas lanchas realizam as viagens mais custosas subindo o rio até a cidade de Tabatinga, atendendo 16 municípios que possuem demanda neste percurso. A capital amazonense é detentora de uma circulação fluvial incomparável na região e de uma notável divisão territorial do trabalho típica do meio técnico-científico-informacional. Exerce, desta maneira, o 
comando primário que sedia as empresas/armadores e os fluxos primordiais para a realização da gestão desta rede de transportes no rio Solimões.

A lancha Crystal I é a maior e mais estruturada embarcação dos fluxos primários (Figura 1), atende rigidamente aos regulamentos e normas da navegação e de segurança naval. Percorre os 1.620 km entre Manaus e Tabatinga em 36 horas. Leva enfermeiros, cozinheiras, comandantes habilitados e tripulação uniformizada realizando os serviços de bordo em todos os turnos, pois a viagem é contínua. A composição dos passageiros se baseia em profissionais liberais, comerciantes e funcionários públicos; assim como aqueles que não se agradam ao transporte aéreo.

Há 7 lanchas da empresa Ajato que operacionalizam os fluxos primários com rota compreendendo o rio Solimões, são elas: Crystal I; Glória de Deus III; Madame Crys; Cidade de Manaquiri; Puma; Ajato 2000 e Belíssima. Estas lanchas zarpam de Manaus produzindo fluxos com até 10 viagens semanais. Transportam entre 65 (Lancha Puma) e 130 passageiros (Lancha Crystal I) com passagens que variam de acordo com o destino, entre 200 a 800 reais atualmente.

As passagens das lanchas são vendidas em guichês da própria empresa Ajato em Manaus e Tefé, ou são disponibilizadas por representantes de vendas que ganham $5 \%$ do valor das passagens. Devido à rarefação de "canais eletrônicos financeiros"ii (CONTEL, 2006) no interior do Amazonas que facilitam a dispersão dos serviços bancários pelo território, não há vendas de passagens no cartão de crédito/débito e pela internet. Ou seja, apesar das lanchas representarem uma modernização dos objetos de transporte no Solimões não há o acompanhamento das estruturas técnicas que deveriam suprí-las.

Em Tabatinga, as lanchas Ajato ancoram em um dos três atracadouros da cidade, o PORTOBRÁS ou "Porto do Voyager", pertencente à empresa dos navios-motores Voyager. Isto ocorre devido à inatividade do Terminal Hidroviário de Tabatinga, uma "Instalação Portuária Pública de Pequeno Porte" (IP4) sob gestão da Administração Hidroviária da Amazônia Ocidental (AHIMOC). Em Tefé o Terminal do Ajato propicia a atracação o que não ocorre em Tabatinga mesmo esta possuindo fixos especializados à navegação superiores ao de Tefé. Neste caso, todas as embarcações que chegam em Tabatinga se emparelham para atracar, embarcar e desembarcar no Flutuante da Portobrás ao custo de 150 reais 
aos armadores.

Ressalta-se que as lanchas dos fluxos primários efetuam uma territorialidade útil à integração territorial por representarem o único segmento do transporte fluvial do Solimões que atende a todas as cidades do grande trecho ManausTabatinga. Atendimento que os segmentos concorrentes não realizam, Naviosmotores (N/M) e Ferry-boats (F/B), em razão da competitividade e às demandas inerentes à circulação de determinadas cidades como Tefé no Médio Solimões.

Neste sentido, verificou-se uma dialética espacial (SILVEIRA, 1999a) quando do uso de equipamentos modernos e contemporâneos das lanchas destes fluxos primários e as estruturas deficientes e precárias dos fixos especializados na navegação regional do rio Solimões. Para mitigar possíveis problemas do percurso, a tripulação possui qualificação para atender aos obstáculos infraestruturais e técnicos provenientes de uma configuração territorial limitada; produto da gestão pública aquém de providenciar melhorias para a navegação de embarcações rápidas no Solimões.

Isto, porém, não impede o uso do território pelas lanchas que tem a velocidade como principal oferta frente aos seus concorrentes. As lanchas dos fluxos primários territorializam este subespaço adaptando suas operações às condições adversas deste subespaço.

\section{2 - As lanchas dos fluxos secundários do rio Solimões}

Estas lanchas dos fluxos secundários zarpam, principalmente, do Terminal do Ajato em Tefé; com configurações, preços e estruturas menores que as lanchas primárias, realizando um territorialidade diferente e um bom papel para a integração territorial, pois além de circularem em trechos análogos aos das lanchas primárias também atendem rotas que compreendem os rios Japurá, Juruá, Tefé e Uarini afluentes do Solimões

David e Nogueira (2010) afirmam que o aumento da procura dessas lanchas da navegação fluvial amazônica tem sido significativo, provocando uma mudança no padrão de navegação da Amazônia, pois alguns deslocamentos que eram feitos em dias são realizados em algumas horas pelas lanchas que priorizam o transporte de passageiros ao de cargas sendo por isso mais leves e rápidas. 
Nesta perspectiva, reflete-se sobre as palavras de Monié (2011, p.160) quando:

(...) para garantir a continuidade dos fluxos e articular de forma eficiente todas as escalas geográficas os integradores logísticos procuram eliminar as hierarquizações espaciais desenvolvendo estratégias que heterogeneizam o mesmo espaço na medida em que a explosão de fluxos pequenos requer mecanismos de centralização destes fluxos para criar ordem e economia de escalas (MONIÉ, 2011, p.160).

Sob esta percepção, observou-se que as cidades de Tefé e Tabatinga efetuam um papel de entrepostos fluviais referenciais na região; tendem a centralizar os fluxos de pequena e média distância e de alta frequência criando uma consequente ordem e economia das escalas. A fluidez territorial é viabilizada via a especificidade técnica e normativa do território (ARROYO, 2015, p.44), neste subespaço essa fluidez possui estas duas cidades como importantes nós da rede de circulação.

Como agentes de integração territorial, pois levam repercussões econômicas de um lugar ao outro via as pessoas que transporta, estas lanchas usufruem das estruturas locais e ao mesmo tempo exigem sua funcionalidade para conectar as pequenas cidades e as cidades intermediárias ou regionais (Tefé e Tabatinga) e destas para a metrópole manauara. Neste contexto, a hierarquia dos fluxos estabelecidos a partir de sua origem, providencia identificar os pontos onde há uma modernização seletiva. No caso de Tefé, Tabatinga e a grande Manaus se configuram como centros de alta fluidez (Figura 4).

Figura 4 - O espaço de atuação das Lanchas dos fluxos primários e secundários. 


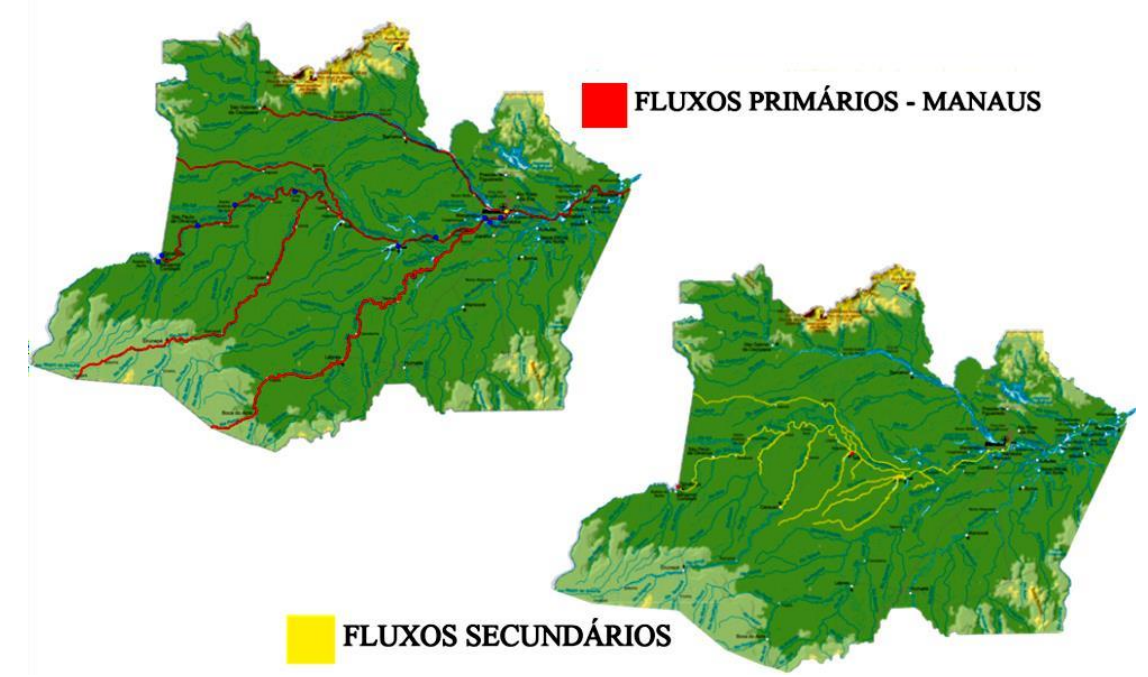

Fonte: Confecção própria, 2017.

Estes "fluxos virtuosos para a integração" (QUEIROZ, 2018) irradiados a partir destes centros urbanos beneficiam as populações distantes restritas ao acesso de transporte que viabilizem uma boa mobilidade regional. As lanchas dos fluxos secundários acessam logradouros, casas flutuantes e comunidades localizadas nas proximidades de seus respectivos trajetos (Figura 5). Levam pequenas encomendas, cartas e recados para os que não possuem acesso aos Correios para comunicar-se, atendendo lugares em que outras embarcações do transporte regional teriam dificuldade sem prejudicar a viagem.

Figura 5 - Municípios atendidos pelas lanchas dos fluxos secundários de Tefé 


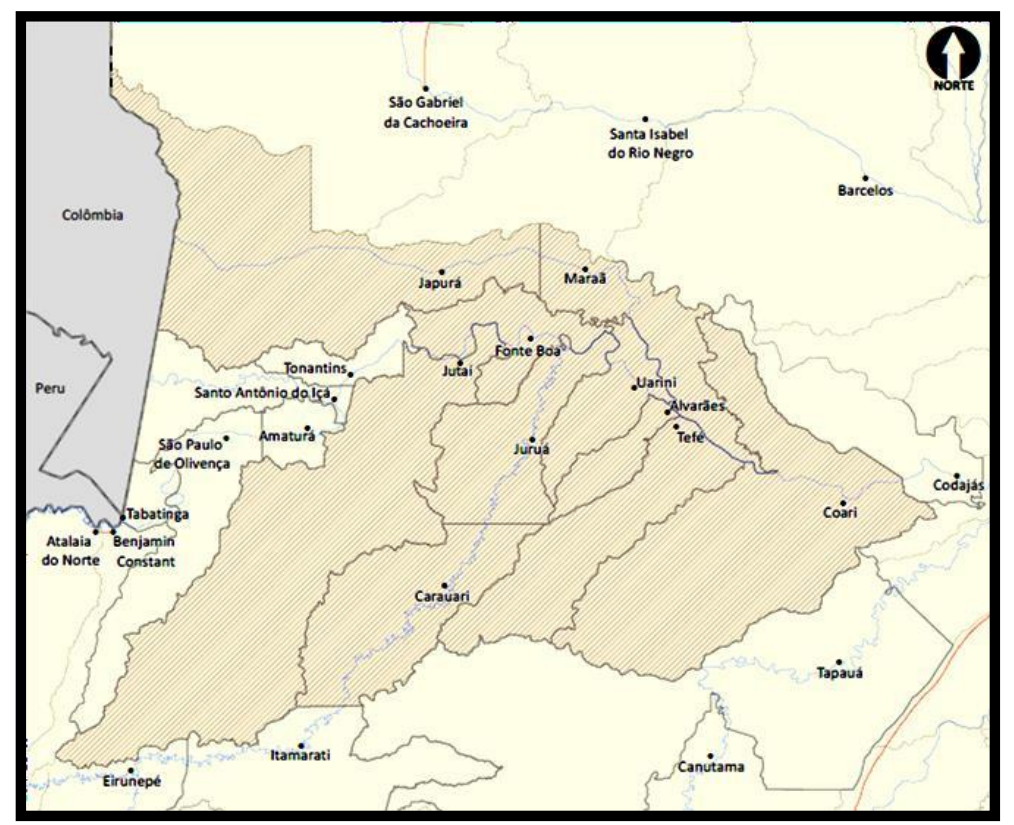

Fonte: Confecção própria, 2018.

Neste espaço distante dos centros econômicos e políticos da formação socioespacial brasileira, os fixos especializados do transporte fluvial na região são limitados. Este cenário de baixa presença de terminais e portos propicia ao "Terminal do Ajato de Tefé" exercer uma expressividade maior em função de sua funcionalidade ser compartilhada com outras embarcações que utilizam suas estruturas para atracar. Possui estruturas e equipamentos diferenciados das instalações rudimentares locais, tais como: i) estrutura de aço ao invés de madeira; ii) gerador de energiaiii; iii) escada para embarque e desembarque de idosos e crianças; iv) guichê de vendas de passagens; v) acesso facilitado no período de seca (praia) e de cheia dos rios; vi) técnicas e organização diferenciadas (lanche, cadeiras, carregadores, taxistas, etc.).

Isto é corroborado pela posição estratégica que Tefé ocupa na rede de fluxos na região, no meio da extensão do rio Solimões, no centro do Amazonas e na foz dos rios Japurá e Tefé. Ressalta-se que Tefé possui apenas um Entreposto Fluvial composto por uma balsa-porto privada e flutuantes de Madeira. Um porto pequeno inaugurado recentemente pelo governo federal ainda esta inoperante.

\subsection{As lanchas dos fluxos terciários do rio Solimões}

As lanchas dos Fluxos Terciários partem de várias cidades do Solimões para as comunidades e localidades ribeirinhas dispersas nos afluentes, furos e igarapés do grande rio. Mantêm suas sedes de assistência técnica e operações 
em Tefé e Tabatinga.

Todavia, apesar destas respectivas lanchas atenderem à solidariedade pertinente ao cotidiano tradicional dos passageiros do Solimões, executam modelos de operacionalização de espaços luminosos. Funcionalizam vetores da globalização como a aceleração e a rapidez, realizando viagens com uso de equipamentos e estruturas vinculadas ao escasso, ao barato, ao disponível e o limitado; providenciando uma territorialidade diferenciada das outras categorias aqui descritas.

Estas lanchas não possuem equipamentos modernos, apenas o design que se assemelha às lanchas que compõem os fluxos primários. Entretanto, buscam melhorar o serviço oferecido pelo transporte regional concorrente realizado pelas canoas com motor rabeta chamadas de "catraias" que se configuram como as embarcações tradicionais da Amazônia Ocidental. Estas são mais lentas e sem cobertura contra o sol ou chuva. Porém, os motores das lanchas deste fluxo terciário são até 20 vezes mais potentes do que uma catraia tradicional, sendo cobrado um custo semelhante ao das catraias. Realiza-se uma modernização com objetos pretéritos, pois mesmo que existam objetos funcionalmente mais ágeis são tecnologias que para o mundo contemporâneo já são antigas, uma modernização pretérita.

Em Tabatinga, os fluxos terciários, partem do chamado "Porto das Catraias", um Entreposto fluvial onde se encontram a sede das atividades da Associação dos Taxistas Fluviais de Tabatinga no "Flutuante Princesa do Alto Solimões"; e da Associação dos Canoeiros Cargueiros de Tabatinga (ACANTURTAB) no "Flutuante Tres Fronteras" onde atuam profissionais peruanos de Santa Rosa, comunidade do outro lado do rio já em território peruano. Estas associações são dois entes institucionais que operacionalizam os fluxos terciários entre Tabatinga e Santa Rosa (Peru) assim como Tabatinga e as cidades de São Paulo de Olivença, Benjamin Constant e Santo Antônio do Iça.

A porosidade e a fluidez territorialiv nesta região da tríplice fronteira são significativas, condicionando sua dinâmica social e econômica (EUZÉBIO, 2011). Enfatiza-se que o abastecimento de Letícia na Colômbia se realiza primordialmente pelo transporte fluvial a partir de Tabatinga no Brasil e lquitos no Peru, pois sua ligação aos centros regionais colombianos é complexa. 
Desta maneira, entre Tabatinga e Santa Rosa, o fluxo diário ultrapassa 100 viagens com os 20 associados da ACANTUTAB. Taxistas da Associação dos Taxistas Fluviais de Santa Rosa afirmam que somando as três associações de taxistas fluviais na tríplice fronteira, ou seja, as duas respectivas associações brasileiras e a peruana, o número de sócios ultrapassa 100 membros. Enfatizase que os armadores colombianos possuem a licença para entrar no Brasil, porém os taxistas brasileiros afirmam que não são bem vindos nos setores fluviais colombianos por não terem acesso à licença necessária para este trânsito. Isto provoca viagens clandestinas pertinentes aos fluxos terciários.

O fluxo entre as cidades de Tabatinga e São Paulo de Olivença compõe-se em torno de 7 viagens diárias (4 horas de duração), bem como entre Tabatinga e Benjamin Constant somam 11 viagens diárias (25 minutos de duração). As viagens de Tabatinga para a cidade de Santo Antônio do Iça possuem poucos fluxos semanais, pois a Associação dos Taxistas Fluviais da própria cidade de Santo Antônio do Iça efetua algumas viagens.

Verificou-se que as lanchas dos fluxos terciários de Tabatinga também efetuam trajetos que as lanchas dos fluxos primários e secundários realizam, apesar de possuírem estruturas menores e não possuírem equipamentos. Estas lanchas terciárias operacionalizam seus serviços de transporte fluvial via a contratação ou fretamentos das viagens e por isso não possuem rotas e horários pré-estabelecidos. Portanto, não cumprem as normas e regulamentos atendidos pelas lanchas dos outros fluxos.

Desta forma, isto gera uma "intercambialidade de objetos" que se realiza pela complexidade entre os níveis e estruturas das lanchas e os fluxos e serviços a serem atendidos por estas. As lanchas dos fluxos terciários promovem a reflexão de que quanto mais distante de Manaus menor a possibilidade de uma plena operacionalização de equipamentos modernos e técnicas mais contemporâneas. Pois, Manaus é o centro dispersor dos fluxos primários, onde há maior densidade de técnicas relacionadas à modernidade, e concomitantemente, à gestão institucional, à assistência técnica, à manutenção das lanchas e onde os elementos que compõem o meio técnico-científico-informacional são mais presentes (Figura 6).

Soma-se a isto, a incapacidade de territórios distantes submetidos a uma 
modernização incompletav (SANTOS, 1994), como Tabatinga, em gerir objetos modernos longe do centro difusor de fluxos, Manaus. Assim como às condições socioeconômicas da população, detentora de um baixo poder aquisitivo, tanto dos passageiros quanto da iniciativa privada local. Desta forma, a demanda, as iniciativas e os investimentos são limitados.

Figura 6 - Principais lanchas dos fluxos terciários de Tabatinga, Santa Rosa (Peru), à esquerda; e Tefé e Coari, à direita.

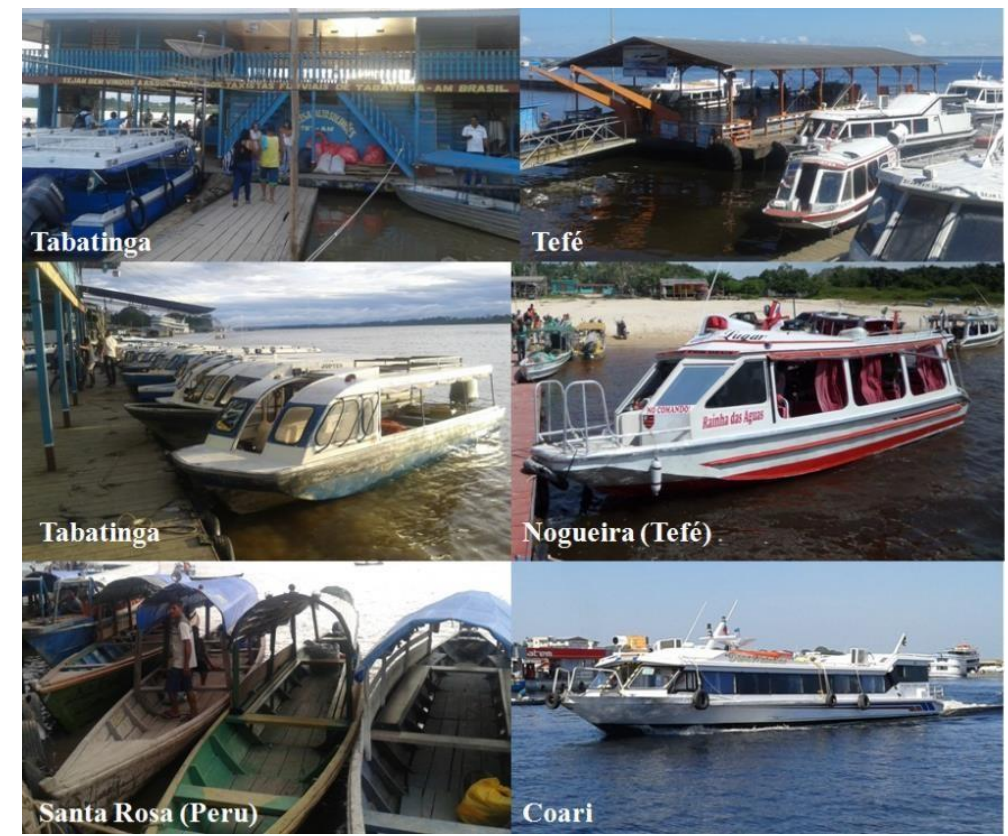

Fonte: Acervo do autor, 2016.

Os fluxos terciários de Tefé são relevantes quando analisados as atividades da Associação dos Catraieiros de Tefé composta por 24 associados, utilizando quatro flutuantes como atracadouros. A maior frequência destes fluxos é para 0 município de Alvarães por intermédio da Vila de Nogueira no rio Tefé. Há uma estrada que liga Nogueira ao município de Alvarães, município pertencente à Microrregião de Tefé juntamente com o município de Uarini. A frequência deste fluxo equivale a 185 viagens semanais efetuados pelas lanchas terciárias.

Em contraponto, muitas catraias tradicionais e voadeiras, concorrentes das lanchas dos fluxos terciários em Tefé continuam realizando seus serviços com destino para as 107 comunidades tradicionais do rio Tefé. A ocorrência de acidentes e mortes neste segmento nos últimos anos motivou os usuários da Microrregião de Tefé e da sua Região de Influência (estudantes, professores, comerciantes e agricultores, etc.) a utilizarem cada vez mais as lanchas dos fluxos 
terciários na região do Solimões.

Fluxos terciários exclusivos da grande comunidade de Caiambé, no rio Tefé, constituídos por lanchas maiores que as que compõem este fluxo em Tabatinga e das com destino a Vila de Nogueira, perfazem os fluxos de até 14 viagens diárias para Tefé em período escolar. Muitas viagens de Caiambé são gratuitas aos passageiros, subsidiadas pela Prefeitura de Tefé para uso de estudantes e professores. Estas lanchas para Caiambé possuem dimensões semelhantes às lanchas dos fluxos secundários, porém não possuem os equipamentos e a potência destas últimas e realizam rotas diferentes, sendo por isso categorizadas nos fluxos terciários. Assemelham-se em forma e conteúdo às operadas no município de Coari vinculados aos armadores terceirizados da Petrobrás no transporte de trabalhadores e funcionários para a Província Petrolífera do Urucu.

\section{AS LANCHAS E SUAS MÚLTIPLAS TERRITORIALIDADES}

A leitura dos fluxos das lanchas de passageiros no Solimões providencia o entendimento de que a territorialidade se realiza considerando "aquilo que a construiu, os lugares em que ela se desenvolve e os ritmos que ela implica" (RAFFESTIN, 1993, p.162). Os diferentes tempos que regem o espaço do Solimões providenciam refletir que as múltiplas formas de relações com o mundo proporcionam diferentes situações e formas geográficas.

Silveira (1999b, p.26) comenta que a situação geográfica "é um cenário para as novas formas de produção e de vida, para novas ações e para a implantação de novos objetos, respondendo a novas racionalidades, a novas intencionalidades, a novos futuros". As situações promovem as ações que devem ser direcionadas para contemplar as necessidades inerentes ou geradas pelas respectivas exigências materiais e imateriais, sociais, políticas, econômicas e culturais. Estas ações levam à criação e o desenvolvimento de objetos geográficos (SANTOS, 1996, p.83) que visam atender a dinâmica social e territorial.

Neste sentido, observa-se que a necessidade e a ação do Sr. Aguiar (idealizador das lanchas de transporte de passageiros e proprietário da empresa Ajato que em 1993 criou o estilo "manauara" do designe das lanchas) conduziram à reprodução de formas diferenciadas do mesmo objeto por outros agentes e 
sujeitos do extenso rio Solimões. Estas distinções da forma das lanchas se desenvolveram para atender às necessidades e funções primordiais que estes "barcos rápidos" podem oferecer sob as condições precárias do ambiente da navegação regional; que representam resistências à circulação oferecida em função das diferentes configurações técnicas e estruturais do território. Cita-se como vetores de resistência à navegação no Solimões à natureza física do grande rio com fenômenos vinculados: ao regime de cheia e seca, aos bancos de areia submersos, materiais despojados na superfície da água, fortes temporais, rebojos, o percurso que se assemelha a um labirinto constituído de furos, igarapés, paranás, etc.

Entrementes, as lanchas inseriram equipamentos e técnicas que os outros segmentos da navegação regional não incorporavam visando o melhor uso do território; incorporando aceleração com potentes motores; disponibilizando, em lugar das redes para os passageiros dos barcos tradicionais, as poltronas das lanchas no estilo dos ônibus do transporte rodoviário em uma região sem rodovias; oferecendo o serviço de atendentes que se assemelham aos serviços dos comissários do transporte aéreo. Ressalta-se que as lanchas dos fluxos primários mantêm a presença de uma tripulação apta a atender os possíveis problemas relacionados à carência de assistência técnica longe de centros urbanos como Manaus. Entre os equipamentos adotados pelas lanchas pertinentes ao meio geográfico contemporâneo cita-se: o ecobatímetro; GPS ou localizador por satélite; potentes holofotes de iluminação e de radiocomunicação; equipamentos de monitoramento dos motores de alta potência e a presença de enfermeiros para possíveis problemas a bordo frente às grandes distâncias amazônicas.

A aceleração conquistou muitos clientes visto que uma viagem de Manaus para Tefé, por exemplo, possui a duração de 36 horas de barco tradicional ou recreio, enquanto que em uma lancha Ajato esta viagem leva 12 horas.

A velocidade e a rapidez bem como os equipamentos e atendimento diferenciado proporcionaram a rápida difusão do modelo de operacionalização destas lanchas no interior do Amazonas. No entanto, as reproduções deste modelo de embarcação por armadores da região não promoveram formas espaciais fiéis aos objetos originais; apenas o design manauara e os motores para velocidade permaneceram. Todavia, as lanchas dos fluxos secundários mantêm 
alguns equipamentos e técnicas referentes às lanchas dos fluxos primários, incorporados de forma artesanal, porém as lanchas dos fluxos terciários realizam uma desobediência às formas originais, pois são vinculadas à menor acessibilidade aos equipamentos e técnicas modernas nos lugares onde atuam.

Estes barcos rápidos que atuam no rio Solimões proporcionam a reflexão sobre 0 atendimento às populações ribeirinhas e a territorialidade empreendida via as interações sociais e estratégias efetuadas com os agentes e sujeitos locais. Desta forma, a territorialidade destas lanchas se vincula à ocorrência de situações geográficas solidárias nesta categoria secundária dos fluxos das lanchas; cita-se o fato do desembarque e embarque de passageiros serem realizadas em comunidades não atendidas pelos outros segmentos do transporte fluvial regional, longe dos nodais que disponibilizam fixos da navegação e dos passageiros oriundos destas comunidades distantes dos centros urbanos nos rios Solimões, Japurá, Juruá e Uarini.

Desta forma, evidencia-se que uma reterritorialização foi empreendida pelas lanchas via a inclusão em seus trajetos de certos lugares antes excluídos ou ignorados no percurso dos barcos tradicionais, em respeito à sua rota e ao prazo estabelecido previamente.

Outro exemplo de uma reterritorialização por estas lanchas secundárias é a entrega de mensagens, cartas, documentos e pequenas encomendas aos moradores de comunidades e casas ribeirinhas; ou seja, estas lanchas alcançam lugares onde os Correios não chegam, realizando os serviços de comunicação e integração que os Correios deveriam cumprir.

A territorialidade realizada pelas lanchas dos fluxos secundários é condicionada aos ritmos e necessidades das pessoas do percurso. O respeito aos percursos e trajetos da viagem se desmancha frente às novas necessidades impostas pelo cotidiano dos passageiros. A racionalidade cabocla vinculada à solidariedade inerente ao espaço de todos ou espaço banal (SANTOS, 1996, p.322) se impõe frente aos espaços de fluxos rigidamente respeitados pelas lanchas dos fluxos primários proveniente de Manaus; estas levam repercussões e ideias da racionalidade hegemônica entendida e absorvida por alguns, mas compreensível e não atendida por outros. Desta maneira, as lanchas desenvolvem sua territorialidade de múltiplas formas à medida que se distanciam 
da capital do estado do Amazonas.

No caso das lanchas dos fluxos terciários a territorialidade efetuada já não atende aos relógios e nem prazos, zarpando para as viagens na medida em que a quantidade dos passageiros seja o suficiente par pagar os custos da operacionalização do trajeto; propiciando que um cliente/passageiro possa pagar sozinho o preço total do percurso não acarretando prejuízo aos armadores. Frente a esta forma de contrato e operacionalização, a aceleração é vista com outros olhos por aqueles clientes pertencentes ao narcotráfico e à pirataria (ratos d'água) na tríplice fronteira. Estes têm as cidades de Tabatinga no Brasil, Letícia na Colômbia e à Vila de Santa Rosa no Peru como o palco para uma fluidez territorial que desrespeita os ditames da racionalidade hegemônica que preza a fiscalização e o atendimento dos prazos.

A territorialidade das lanchas dos fluxos terciários é especial e peculiar, pois efetuam seus serviços para quem lhe pagar e mostrar o destino. De Tabatinga e Santo Rosa no Peru seus fluxos acabam corroborando para a instabilidade territorial; no entanto, estas lanchas são fundamentais para sua clientela constituídas por pequenos agricultores, vendedores, estudantes, professores da rede pública rural e pequenos comerciantes, etc.

Sendo assim, a alta fluidez e porosidade territorial funcionalizada pelos fluxos terciários em Tefé e Tabatinga proporcionam a leitura de uma desterritorialização fortalecida, concomitantemente, à baixa fiscalização e gestão do território pelas instituições competentes à circulação fluvial. Este cenário que exibe a incipiência na atuação e presença dos órgãos do estado permite que o Solimões relativize seus status de hidrovia e se adéque a uma forma de "Via Navegável".

De acordo com Sack (2013, p.78) a territorialidade "é uma estratégia para estabelecer diferentes níveis de acesso a pessoas, coisas e relações". Contextualiza-se que a lógica do controle do território do Solimões pelas lanchas se realiza através dos fluxos destas. A aceleração permite que a fluidez, o contato, o movimento afete, influencie e controle os fluxos de ideias e recursos que contemplem as necessidades dos sujeitos sociais a partir desta interação realizada com a velocidade estabelecida pelos fluxos acelerados das lanchas. Atuando, concomitantemente, com a lentidão dos barcos tradicionais. 
Nesta dialética espacial expressado pelo encontro entre o rápido e o lento, o pretérito e o contemporâneo, a circulação se estabelece como meio de produção fundamental em espaços periféricos (QUEIROZ, 2018). Becker (2013) afirma que as cidades da Amazônia não possuem dinamismo e dependem das trocas entre elas para seu desenvolvimento. Neste contexto, Queiroz (2017b) discute que os fluxos que compõem a centralidade periférica de cidades do Solimões, como Tefé, permite a autonomia econômica e social.

Neste sentido, as lanchas possibilitam a aceleração destes fluxos da centralidade, uma velocidade útil para as trocas e a circulação de passageiros, mesmo que ainda atuem os barcos tradicionais. Estas lanchas desenham novos rumos, assumem novos lugares e estabelecem novos nodais em função dos novos interesses de sujeitos sociais; assim como de agentes de lugares distantes (armadores) e os passageiros locais e internacionais com necessidades advindas das novas maneiras de se relacionar com a rapidez proveniente da aceleração. Ressalta-se que a Amazônia é destino de muitos turistas do mundo e a hidrovia do rio Solimões liga Manaus (Brasil), a dois países (Colômbia e Peru) é o acesso a muitos recantos naturais amazônidas.

A "territorialidade é sempre construída socialmente" e para isso ela envolve "múltiplos níveis de razões e significados" (SACK, 2013, p.87). Neste contexto Sack (2013) discute que:
A territorialidade pode ter implicações normativas também. Deixar lugares de lado e aplicar níveis de acesso significa que indivíduos ou grupos têm removido algumas atividades e pessoas de lugares e incluído em outros. Isto é, eles têm estabelecido diferentes níveis de acesso a coisas. Portanto, a territorialidade forma o pano de fundo para relações espaciais humanas e concepções de espaço e indica que as relações espaciais humanas não são neutras (SACK, 2013, p.87).

Neste sentido, as relações geradoras dos fluxos tendem a corroborar para uma territorialidade que valoriza certos nodais ou porções do território. A disponibilidade da aceleração a muitos passageiros do Solimões só é viabilizado pelas lanchas do transporte fluvial. Estes estão inseridos num cenário de uma circulação fluvial envolta a desafios institucionais, infraestruturais e administrativos (QUEIROZ, 2017a). Onde o roubo de cargas, a ineficiência nos 
portos e a carência de terminais são os maiores problemas segundo os proprietários de embarcações (CNT, 2013, p.151). Isto revela a necessidade de ajustes provenientes de políticas públicas bem como fiscalização e uso de normas que não são respeitadas.

Este contexto espacial provoca uma desterritorialização proveniente da atuação de sujeitos causadores de uma instabilidade territorial que leva aos armadores das lanchas a buscarem lugares seguros e aptos a atender a demanda de passageiros. Isto ocorre principalmente nos fluxos terciários onde as lanchas são submetidas às rotas traçadas pelas necessidades e interesses do cotidiano, sem um planejamento prévio e um destino padronizado como os estabelecidos pelos fluxos primários e secundários. Mesmo que as lanchas dos fluxos secundários embarquem e desembarquem pessoas em determinados lugares do percurso não o fazem de maneira definitiva, pois a rota é a mesma em todas as viagens. Porém, as lanchas dos fluxos terciários por estarem expostas a rumos instáveis promovem uma territorialidade diferenciada. $\mathrm{O}$ "território da instabilidade" da navegação no Solimões pode não apenas restringir e conter, mas também excluir passageiros tais como turistas e comerciantes em razão da insegurança na região; e mesmo excluir fluxos ligados às atividades de bancos e instituições, o que ocorreu após o sequestro e roubo de lanchas vinculadas ao banco Bradesco entre as cidades de Tonantins e Jutaí em 2015 (QUEIROZ, 2017b).

No entanto, as lanchas dos fluxos primários, além da velocidade oferecem radiocomunicação com a Capitania dos Portos e sistema de posicionamento por satélite para alertar as autoridades. Assim, alguns problemas relacionados aos empecilhos que causam insegurança e instabilidade podem ser precavidos e mesmo sanados por estas lanchas primárias. Ou seja, ocorre uma reterritorialização a partir da atuação e uso de instrumentos e equipamentos modernos que propiciam uma territorialidade pós-moderna a partir de um território-rede (HAESBAERT, 2011, p.349).

Haesbaert (2011) discute que a reterritorialização é um processo associado à multiterritorialização e desterritorialização, conceitos que são espacialmente descontínuos e extremamente complexos. O autor anuncia que a territorialização deve ser trabalhada na multiplicidade de suas manifestações e poderes 
incorporados a partir de múltiplos agentes. Neste sentido, o papel dos passageiros, dos indivíduos, dos grupos sociais, das instituições públicas, armadores e empresas se configuram como essenciais para compreender o feixe de relações que constrói múltiplas territorialidades.

A forte presença destes sujeitos sociais e entes institucionais em Manaus e a fraca atuação destes em Tefé e Tabatinga fornece subsídios para o entendimento de diferentes formas das lanchas no usar, afetar, influenciar e controlar os fluxos que acessam o território e fazem dele um objeto de análise social.

Neste sentido, a iniciativa privada de Manaus representada principalmente pela Empresa Ajato possui opções de incorporar novos dados e equipamentos disponíveis na metrópole inserindo nas lanchas dos fluxos primários. Porém, os empresários/armadores do Solimões não empreendem tanto, pois seus recursos limitados o que restringe suas iniciativas. Frente à escassez de investimentos e construção de novos fixos, os fluxos já estabelecidos se valorizam e permanecem significativos em função da dependência pela população local da circulação fluvial num subespaço sem estradas e ferrovias.

Sendo assim, as lanchas se adaptam à configuração diversa proveniente da seletiva capacidade do território em sediar técnicas e objetos úteis à navegação; como consequência as formas das lanchas são modificadas com o intuito de atender a demanda significativa de passageiros, oferecendo a aceleração como característica diferencial nestas viagens que acabam por promover territorialidades múltiplas a partir da funcionalidade do mesmo objeto geográfico.

\section{CONSIDERAÇÕES FINAIS}

Os fluxos que providenciam o acesso da aceleração aos espaços letárgicos no rio Solimões a partir das lanchas do transporte fluvial de passageiros exibem diferentes e múltiplas territorialidades.

A leitura destas territorialidades por intermédio das lanchas dos fluxos primários, secundários e terciários oferece subsídios para compreender que as formas destes barcos rápidos se modificam na medida em que as necessidades e funções se adaptam à estrutura técnica e normativa do território. A configuração territorial possibilita a adequação e desenvolvimento de novas formas de uso do 
território e controle dos fluxos que interagem com as exigências do cotidiano dos diversos tipos de passageiros do Solimões.

A leitura da atuação das lanchas dos fluxos primários evidencia a ocorrência de uma "territorialidade técnica" efetuada a partir do uso de técnicas e equipamentos modernos no uso do território. Verificou-se que as lanchas dos fluxos secundários promovem uma "territorialidade solidária" onde serviços de entrega de mensagens e encomendas assim como 0 atendimento às comunidades e casas ribeirinhas distantes dos nodais regionais e localizadas na rota destas lanchas são direcionados.

Desta forma, estas lanchas dos fluxos primários e secundários realizam uma reterritorialização, incluindo, servindo e permitindo que as lanchas possam reinserir estas pessoas via o transporte fluvial veloz e rápido ao cotidiano social; com técnicas e estratégias que criam novos significados e novas atribuições vinculadas às necessidades do cotidiano frente à escassez de infraestruturas e assistência no território.

Entrementes, a análise das lanchas dos fluxos terciários do Alto Solimões evidencia uma "territorialidade desobediente" às formas espaciais tanto das lanchas que se tornam uma cópia em miniatura do modelo "manaura" que as caracterizam como do uso das rotas no território, pois os armadores oferecem seus serviços para quem lhe pagar e mostrar o destino. Assim, apesar de transportarem passageiros diversos como: pequenos agricultores, vendedores, estudantes, professores da rede pública rural e pequenos comerciantes, etc. $O$ desrespeito à especificidade técnica e normativa que permite a fluidez territorial e que corrobora para a instabilidade territorial vinculada à presença dos piratas dos rios (ratos d'água) e narcotraficantes constata que há uma desterritorialização proveniente à fraca atuação das instituições públicas de controle e gestão do território no rio Solimões.

No entanto, o duelo de objetos advindo das diferentes formas das lanchas estabelece o símbolo da diminuição da duração das viagens fluviais no enorme rio Solimões. Isto exibe as múltiplas territorialidades destes objetos representantes de uma especialização do lugar e do avanço inexorável da técnica e da aceleração típica de espaços luminosos globais nesta fração da formação socioespacial brasileira. 
Arroyo, m.; cruz, r. C. A. (orgs). Território e circulação: a dinâmica contraditória da globalização. São paulo: annablume, 2015.

Becker, b. K. A urbe amazônida: a floresta e a cidade. 1a ed. Rio de janeiro: garamond, 2013.

Confederação nacional dos transportes (cnt). Pesquisa cnt da navegação interior 2013. Brasília: cnt, 2013.

Contel, f. B. Território e finanças: técnicas, normas e topologias bancárias no brasil. Tese de doutorado - programa de pós-graduação em geografia humana faculdade de filosofia, letras e ciências humanas da universidade de são paulo.orientadora: prof ${ }^{\mathrm{a}}$. Dr ${ }^{\mathrm{a}}$. Maria laura silveira. São paulo, 2006.

David, r. C. A.; nogueira, r. J. B. O transporte fluvial expresso: um novo segmento na rede fluvial amazônica. Xvi encontro nacional dos geógrafos. Anais. Porto alegre: jul. 2010.

Euzébio, emerson flávio. Fronteira e horizontalidades na amazônia: as cidades de gêmeas de tabatinga (brasil) e letícia (colômbia). Dissertação de mestrado programa de pós-graduação em geografia humana - faculdade de filosofia, letras e ciências humanas da universidade de são paulo.orientadora: profā . Drª . Mônica arroyo. São paulo, 2011.

Haesbaert, rogério. O mito da desterritorialização - do "fim dos territórios" à multiterritorialidade. Rio de janeiro; bertrand brasil, 2011.

Harvey, d. A produção capitalista do espaço. São paulo: annablume, 2005.

Monié, frédéric. Dinâmicas produtivas, logística e desenvolvimento territorial. In: videira, sandra lúcia; costa, pierre alves; fajardo, sérgio. Geografia econômica: (re) leituras contemporâneas. Rio de janeiro: letra capital, 2011.

Queiroz, k. O. Entre motores e velas - os racionamentos e interrupções de energia elétrica no amazonas. Curitiba: editora crv, 2012.

Queiroz, k. O. Globalização e integração territorial - o caso da região de tefé no amazonas. Confins revue. Vol. 35. N.35. Paris: 2018.

Queiroz, k. O. O transporte fluvial no solimões: o caso das lanchas ajato. In: xii encontro nacional da associação nacional de pós-graduação e pesquisa em geografia - xii enanpege. Proto alegre, 12 a 15 out. 2017. Anais do xii encontro nacional da associação nacional de pós-graduação e pesquisa em geografia - xii enanpege. Porto alegre: ufrgs, 2017a. P.10.093-10.104.

Queiroz, k. O. Integração e globalização relativizada - uma leitura a partir de tefé no amazonas. Manaus: uea edições, 2017b.

Raffestin, c. Por uma geografia do poder. São paulo: ática, 1993.

Sack, r. D. O significado de territorialidade. In: dias, leila christina; ferrari, maristela (orgs). Territorialidades humanas e redes sociais. Florianópolis: editora insular, 2013.

Santos, m. A natureza do espaço: técnica e tempo, razão e emoção. $4^{\underline{a}}$ ed. São paulo: editora da universidade de são paulo, 2009 [1996].

Santos, m. Por uma economia política da cidade: o caso de são paulo. São paulo: editora hucitec/educ, 1994.

Silveira, m. L. Um país, uma região: fim de século e modernidades na argentina. São paulo: fapesp/laboplan-usp, 1999a.

Silveira, m. L. Uma situação geográfica: do método á metodologia. Revista território. Ano iv, no 6, jan/jun, 1999b. 


\begin{abstract}
i Armador é a pessoa física ou jurídica que equipa, mantém e explora comercialmente a embarcação mercantil, podendo ser ou não proprietário dela. (CNT, 2013, p. 272).

ii Tais como: expressos ou caixas eletrônicos, os pontos de recebimento de cartão de crédito e débito, redes de internet banking, centrais de atendimento telefônico, etc. (CONTEL, 2006, p.253). iii Todos os 62 municípios do estado do Amazonas sofrem interrupções e racionamentos de energia elétrica, por esse motivo o gerador de energia é fundamental nesta região (QUEIROZ, 2012).

iv A porosidade territorial vinculada a uma fluidez territorial (ARROYO, 2001) que viabiliza as trocas mercantis e econômicas na borda do território, negligenciando muitas vezes, a presença e a fiscalização do Estado em suas obrigações de guarda, manutenção e defesa da soberania frente aos modernos sistemas de informação, comunicação e redes de transportes privados que nem sempre podem ser regulados e interceptados (QUEIROZ, 2017, p.30).

$\checkmark$ Modernização seletiva proveniente do esforço que países do terceiro mundo realizam para construir infraestruturas em detrimento de investimentos sociais.
\end{abstract}

